Florida International University

FIU Digital Commons

Electrical and Computer Engineering Faculty

Publications

2016

Performance evaluation of optimal photovoltaic-electrolyzer system with the purpose of maximum Hydrogen storage

Arash Khalilnejad

Aditya Sundararajan

Arif I. Sarwat

Follow this and additional works at: https://digitalcommons.fiu.edu/ece_fac

Part of the Electrical and Computer Engineering Commons

This work is brought to you for free and open access by the College of Engineering and Computing at FIU Digital Commons. It has been accepted for inclusion in Electrical and Computer Engineering Faculty Publications by an authorized administrator of FIU Digital Commons. For more information, please contact dcc@fiu.edu. 


\section{Performance Evaluation of Optimal Photovoltaic-Electrolyzer System with the Purpose of Maximum Hydrogen Storage}

\author{
A. Khalilnejad \\ Student Member, IEEE \\ Electrical Engineering Department, \\ Center of Energy, Power \& \\ Sustainability (EPS), \\ Florida International University \\ (FIU), Miami, USA \\ akha1026@fiu.edu
}

\author{
A. Sundararajan \\ Student Member, IEEE \\ Electrical Engineering \\ Department, Center of Energy, \\ Power \& Sustainability (EPS), \\ Florida International University \\ (FIU), Miami, USA \\ asund005@fiu.edu
}

\author{
A.I. Sarwat \\ Senior Member, IEEE \\ Electrical Engineering Department, \\ Center of Energy, Power \& \\ Sustainability (EPS), \\ Florida International University \\ (FIU), Miami, USA \\ asarwat@fiu.edu
}

\begin{abstract}
Power electronics-based electrolyzer systems are prevalently in current use. This paper proposes the more recently employed directly coupled photovoltaic (PV) electrolyzer systems. Equipped with accurate electrical models of the advanced alkaline electrolyzer, PV system and Hydrogen storage tank simulated using MATLAB, the system's performance for a full week is analyzed using Miami, Florida's meteorological data. A multi-level Genetic Algorithm (GA)based optimization facilitates maximum hydrogen production, minimum excess power generation, and minimum energy transfer loss. The crucial effect of temperature on the overall system performance is also accounted for by optimizing this parameter using GA, maintaining operating conditions close to the Maximum Power Point (MPP) of the PV array. The results of the analysis have been documented to show that the optimal system for a $10 \mathrm{~kW}$ electrolyzer can produce, on an average, Hydrogen of $0.0176 \mathrm{~mol} / \mathrm{s}$, when the system is operating with $6.3 \%$ power loss and $2.4 \%$ power transfer loss.
\end{abstract}

Index Terms-- Photovoltaic, Advanced alkaline electrolyzer, Genetic Algorithm, Hydrogen production, directly coupled system

\section{INTRODUCTION}

Energy generation and storage have gathered enough prominence and momentum in the recent years owing to an ever-increasing demand for them. Lending to the expanding research efforts in this field is the inclusion of the prospect of considering PV systems as the popular mode of power production, considering their eco-friendly features, cleanliness, abundance, cost-effectiveness and sustainability [1], [2]. However, PV is a very intermittent source of power that depends on a wide range of meteorological, geographical and temporal characteristics. Even over a day, the extent of solar irradiation received by the Earth at one place changes dramatically, raising concerns related to reliable power generation, and in turn reliable conversion to fuel. In [3]-[5], the choice of Hydrogen has been proposed due to its high energy density, low energy loss, onsite provision capabilities, and innate compactness. Water electrolyzer is regarded as one of the most yielding ways to tap the latent power of PV systems by using the electricity generated by them to generate

This work is supported by the National Science Foundation under Grant No. 1541108. Any opinions, findings, conclusions or recommendations expressed in this material are those of the authors and not necessarily reflect the views of NSF.
Hydrogen from water by the chemical process of electrolysis. This follows from the fact that the overall system efficiency is enhanced by their matching electrical characteristics.

Several efforts have been initiated and proposed in [6]-[9] for the efficient design of a combined PV electrolyzer system. A study in 2008 appraised the operation of a coupled PVelectrolyzer system with a controlled DC-DC converter [10]. In it, the safe optimum searching algorithm is used to deliver the MPP for the PV system, besides controlling a buck-boost converter which ties the PV array with the electrolyzer. Albeit the use of power electronic devices for ensuring optimal power transfer between systems [11], [12], the edge gained by the utilization of directly coupled systems is the reduction of cost and overall system complexity. This is a consequence of the optimal design of the system facilitating the accurate synchronization of the MPP of PV with the electrical characteristics of the electrolyzer, and the overall improvement in the renewable-hydrogen hybrid system economics. A 2009 study designed a directly coupled PV system with a Proton Exchange Membrane (PEM) electrolyzer with multiple levels of safety and operational redundancy to demonstrate the system's fail-safe functioning [13]. While a 2010 evaluation designed and analyzed the operation of a directly coupled PV power regulator for standalone hydrogen generation power systems [14], a few other initiatives have shed light on the estimation of the optimal operational set points and size of the directly coupled PV-electrolyzer. Reference [15] presented a directly coupled PV-PEM electrolyzer to relatively size the components based on simple modeling of both polarization curves. The professed optimization aimed to minimize the energy transfer loss. As documented in [16], the energy exergy methodology was adopted to propose a novel integrated system which married the aspects of photo-catalysis, PV, thermal engine and chemical energy storage, promising a better solar energy harvesting. In the same year, a multi-objective optimization of directly coupled PV-electrolyzer systems using Imperialist Optimization Algorithm (IOA) was proposed [17], which claimed minimal energy transfer loss, defined by the difference between the MPP power and that of the system. In 
a similar study, Particle Swarm Optimization (PSO) was used to maximize hydrogen generation by optimizing the size and operating conditions of the electrolyzer, which in-turn is directly connected to the PV [18]. In all of the aforementioned studies, reduction of the energy transfer loss defined earlier has been the primary objective. However, [19] conducted an extensive study on the optimization and sensitivity of directly coupled PV-electrolyzer system in Beijing. The ratio of actual voltage to that of MPP, denoted by $\mathrm{V} / \mathrm{Vm}$, was coined to analyze the Efficiency Changing Point (ECP), which can in-turn be defined as the working point that differentiates the varying trends of the system efficiency. Most recently, in 2015, an optimum analysis of PV-driven electrolyzer system for hydrogen generation was analyzed. This algorithm focused on maximizing hydrogen production through numerical calculation methods, accounting for solar irradiance, the electrolyzer's operating temperature and its band-gap energy [20].

Optimization of the PV system's electrical production, compounded by maximal Hydrogen production and minimal excess power, in order to bring it as close to the MPP as possible forms the premise for this paper. Evaluation of the electrical performance of the hybrid PV-electrolyzer system is also presented in a detailed yet comprehensive manner. Optimal working temperature of the electrolyzer is also accounted for, to enhance the performance by a significant amount. A twofold GA optimization process is hence designed, proposing a new index for optimizing the system. The performance of the proposed system is compared and contrasted with that of the system with DC-DC converter following MPP of the PV [28]-[31]. A simulation-driven operational view of the system for a period of one week is depicted. The results are supported by proper validation, comparing with another study. Fig. 1 shows a schematic diagram of the proposed system.

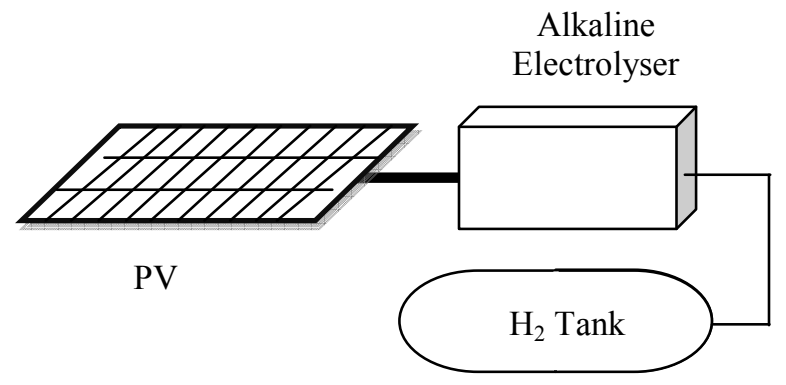

Fig. 1. Simplified schematic of directly coupled PV-Electrolyzer system with hydrogen storage

\section{A. Electrolyzer}

Electrolyzers, more specifically the alkaline, are widely used contraptions for generating hydrogen by electrolyzing water. A liquid electrolyte is required for conducting ions, helping in their exchange between the anode and cathode electrodes. Potassium Hydroxide (KOH) is predominantly used as the electrolyte considering its optimal conductivity and corrosion resistance of the stainless steel. The cathode and anode electrochemical equations are shown below in their balanced form.

$$
\begin{aligned}
& \text { Cathode }: 2 \mathrm{H}_{2} \mathrm{O}_{(l)}+2 e^{-} \longrightarrow \mathrm{H}_{2(g)}+2 \mathrm{OH}^{-}(a q) \\
& \text { Anode }: 2 \mathrm{OH}_{(a q)}^{-} \longrightarrow \frac{1}{2} \mathrm{O}_{2(g)}+\mathrm{H}_{2} \mathrm{O}_{(l)}+2 e^{-}
\end{aligned}
$$

Electrolysis happens only in the presence of electric current. Hence, it can be viewed that with a consistent supply of electric current, there will be a consistent production of hydrogen. If there is a nonlinear load wherein the input voltage varies, as is the case with PV systems, then the rate of hydrogen production correspondingly changes as well. This further warrants an increase in the power which is restricted to the power characteristics of the power delivery source. In [21], the U-I characteristics of an advanced alkaline electrolyzer are defined, mathematically represented below.

$U_{\text {electrobzer, }, \text { ell }}=U_{\text {reversible }}+\frac{r_{1}+r_{2} T}{A} I+s \log \left(\frac{t_{1}+t_{2} / T+t_{3} / T^{2}}{A} I+1\right)$

where $U_{\text {electrolyzer,cell }}$ is the cell terminal voltage $(\mathrm{V}), U_{\text {reversible }}$ is reversible cell voltage $(\mathrm{V}), r_{1}, r_{2}$ are parameters for ohmic resistance $\left(\Omega \cdot \mathrm{m}^{2}, \Omega \cdot \mathrm{m}^{2} /{ }^{\circ} \mathrm{C}\right)$, as the coefficients for ohmic voltage, $s, t_{1}, t_{2}, t_{3}$ are parameters for overvoltage $\left(\mathrm{V}, \mathrm{m}^{2} / \mathrm{A}\right.$, $\left.\mathrm{m}^{2} .{ }^{\circ} \mathrm{C} / \mathrm{A}, \mathrm{n} \mathrm{m}^{2} .{ }^{\circ} \mathrm{C}^{2} / \mathrm{A}\right), A$ is the area of cell electrode $\left(\mathrm{m}^{2}\right), I$ is electrolyzer current (A), and $T$ is cell temperature $\left({ }^{\circ} \mathrm{C}\right)$. $U_{\text {reversible }}$ is given by the Gibbs free energy change of the electrical process as shown below.

$$
U_{\text {reversible }}=-\frac{\Delta G}{z F}
$$

where, $z$ is the number of molecules transferred per hydrogen molecule, equal to $2, \Delta G$ is Gibbs free energy, and $F$ is Faraday constant. Hence, $U_{\text {reversible }}$ can be expressed by an empirical equation as:

$$
U_{\text {reversible }}=U_{\text {reversible }}^{0}-k_{\text {reversible }}(T-25)
$$

where $U^{0}{ }_{\text {reversible }}$ is the reversible cell voltage at standard condition (V), and $k_{\text {reversible }}$ is the empirical temperature coefficient of $U_{\text {reversible }}\left(\mathrm{V} /{ }^{\circ} \mathrm{C}\right)$. For the electrolyzer cells connected in series, the current is the same and the voltage is given by

$$
U_{\text {electrolyzer }}=n_{c} \cdot U_{\text {electrolyzer,cell }}
$$

Knowing the voltage and current of the electrolyzer, the amount of hydrogen generated can be derived by

$$
\dot{n}_{H_{2}}=\eta_{F} \frac{n_{c} I}{2 F}
$$

where $\dot{n}_{H_{2}}$ is the hydrogen production rate (mol/s) and $\eta_{F}$ is the Faraday efficiency. By increasing the current, the ratio of parasitic current at the electrolyte decreases, increasing $\eta_{F}$. The equation of current density is provided below. 


$$
\eta_{F}=\frac{(I / A)^{2}}{f_{1}+(I / A)^{2}} f_{2}
$$

where $f_{1}\left(\mathrm{~mA}^{2} \mathrm{~cm}^{-4}\right)$, and $f_{2}$ are parameters in current efficiency calculation. Since the current from the electrolyzer is dependent on temperature, the current efficiency is also a function of the same parameter. Hence, with a hike in temperature, the resistance of the fluid drops enhancing the efficiency. However, the trend reverses at very high temperatures, where the bulb production generates parasitic currents within the electrolytic fluid, downgrading the efficiency. The ventilation of the electrolyzer is designed to keep the system's temperature a constant. This is despite the variation in temperature observed during the operation of the system because of the thermal operation of the device. Table 1 shows the parameters of the electrolyzer.

TABLE I

PARAMETERS OF ELECTRICAL CHARACTERISTICS OF ALKALINE ELECTROLYZER [22]

\begin{tabular}{cc}
\hline Parameter & Value \\
\hline $\boldsymbol{r}_{1}$ & $7.3 \times 10^{-5} \Omega \mathrm{m}^{2}$ \\
$\boldsymbol{r}_{2}$ & $-1.1 \times 10^{-7} \Omega \mathrm{m}^{2} \mathrm{C}^{-1}$ \\
$\boldsymbol{t}_{\boldsymbol{1}}$ & $-1.002 \mathrm{~A}^{-1} \mathrm{~m}^{2}$ \\
$\boldsymbol{t}_{2}$ & $8.424 \mathrm{~A}^{-1} \mathrm{~m}^{2} \mathrm{C}$ \\
$\boldsymbol{t}_{3}$ & $247.3 \mathrm{~A}^{-1} \mathrm{~m}^{2} \mathrm{C}^{2}$ \\
$\boldsymbol{A}$ & $0.25 \mathrm{~m}^{2}$ \\
$f_{1}$ & $250 \mathrm{~mA}^{2} \mathrm{~cm}^{-4}$ \\
$f_{2}$ & 0.96 \\
\hline
\end{tabular}

\section{B. Hydrogen Storage System}

Physical hydrogen storage technique is used to calculate its storage pressure, coupled with flow rate, as dictated by the following equation.

$$
P_{b}-P_{b i}=z \frac{n_{H_{2}} R T_{b}}{M_{H_{2}} V_{b}}
$$

where $M_{H 2}$ is the molar mass of hydrogen $\left(\mathrm{kg} \mathrm{kmol}^{-1}\right), P_{b i}$, $P_{b}$ are the initial and operating pressures of tank $(\mathrm{Pa})$ respectively, $R$ is the universal gas constant $\left(\mathrm{J} \mathrm{kmol}^{-1} \mathrm{~K}^{-1}\right), T_{b}$ is the operating temperature $(\mathrm{K}), V_{b}$ is the volume of the tank $\left(\mathrm{m}^{3}\right)$, and $z$ is the compressibility factor as a function of temperature.

\section{C. $P V$}

The U-I characteristics, also called the electrical characteristics, of the PV system for different solar radiation levels and temperature values is primarily evaluated for the assessment of solar cells. In [23], [24], many cell models have been developed and proposed depending on the level of accuracy needed in the model chosen for design.

In this study, as shown in Fig. 2, a one-diode model of the PV system denoting the dark current in parallel with PV cells, a shunt resistance and a series resistance is devised and used [32]-[35]. The PV cells are necessarily connected in series and parallel to increase operating voltage and current, thereby causing a climb in the overall output power, which is a parameter inherently dependent on both current and voltage.

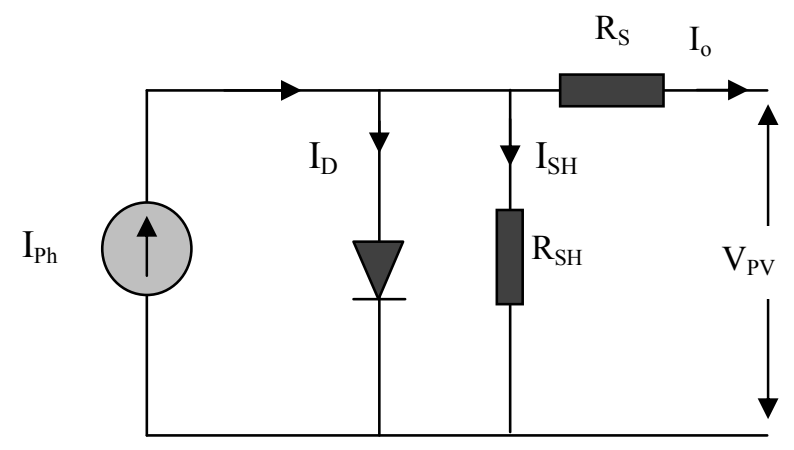

Fig. 2. Model of photovoltaic cell

From the model shown in Figure 2, one can mathematically equate the cell current as given below [25]:

$$
I_{o, \text { cell }}=I_{p h}-I_{d}-I_{s h}
$$

where $I_{p h}$ is the current generated by irradiance (A), proportional to solar irradiation, $I_{d}$ is the current of the diode (A), and $I_{s h}$ is the current of parallel resistor (A). For a PV array that has a combination of various PV cells, the output current is given by:

$$
I_{0}=N_{p} I_{p h}-N_{p} I_{r s}\left[e^{\frac{q\left(V+R_{s} I_{0}\right)}{A . k . T \cdot N_{s}}}-1\right]-N_{p} \frac{q\left(\mathrm{~V}+\mathrm{R}_{\mathrm{s}} \mathrm{I}_{0}\right)}{N_{s} R_{s h}}
$$

where, $I_{r s}(\mathrm{~A})$ is the reverse saturation current of the cell, $k$ is the Boltzman constant, $T$ is the cell temperature (K), $N_{s}$ and $N_{P}$ are the number of PV cells in series and parallel respectively, $q$ is the electron's charge, and $A$ is the p-n junction ideality factor. $I_{p h}$ (A) is proportional to solar irradiance as dictated by the following equation:

$$
I_{p h}=\frac{G}{1000}\left(\mathrm{I}_{\mathrm{SC}}+\mathrm{k}_{\mathrm{i}}\left(\mathrm{T}-\mathrm{T}_{\mathrm{r}}\right)\right)
$$

where, $I_{s c}(\mathrm{~A})$ is the short circuit current, $k_{i}$ is the short circuit current coefficient, $T_{r}$ is the cell reference temperature, and $g$ is the solar radiation. Temperature greatly drives the saturation current of the cells, as shown mathematically below:

$$
I_{r s}=I_{r r}\left[\frac{T}{T_{r}}\right] \exp \left(\frac{q \cdot E_{G}}{k \cdot A}\left(\frac{1}{T_{r}}-\frac{1}{T}\right)\right)
$$

where, $I_{r r}$ (A) refers to the reverse saturation current at a reference temperature, which in turn is dependent to the 
material of the PV cell, $E_{G}$ is the band gap energy of the cells, and $T_{r}(\mathrm{~K})$ is the reference temperature. Table II provides the specifications of the used PV modules.

Attaining MPP state is important for the PV array to deliver maximum power. In other words, the derivative of the produced power to voltage should be zero, as expressed by the sequence of equations below.

$$
\frac{d P}{d V}=0
$$

It implies,

$$
\begin{gathered}
\frac{d P}{d V}=\frac{d(V I)}{d V}=V \frac{d I}{d V}+I=0 \\
\frac{d I}{d V}=-\frac{I}{V} \quad \text { [at MPP] }
\end{gathered}
$$

TABLE II

SPECIFICATION OF THE PHOTOVOLTAIC MODULE

\begin{tabular}{ll}
\hline Parameter & Value \\
\hline$P_{m}$ & $45 \mathrm{~W}$ \\
$V_{O C}$ & $21.93 \mathrm{~V}$ \\
$I_{S C}$ & $2.66 \mathrm{~A}$ \\
$V_{M P}$ & $18.85 \mathrm{~V}$ \\
$I_{M P}$ & $2.47 \mathrm{~A}$ \\
$E_{G}$ & $1.6 \mathrm{eV}$ \\
$A$ & $0.75 \mathrm{~m}^{2}$ \\
$T_{r}$ & $25{ }^{\circ} \mathrm{C}$ \\
$Q$ & $1.6 \times 10^{-19}$ \\
\hline
\end{tabular}

\section{SYSTEM SIMULATION}

There are essentially two ways to integrate PV with electrolyzer. While one involves a direct coupling, the other is via a DC-DC power electronics converter. It has been well documented in literature that the optimal operation of directly coupled systems is reliant on numerous crucial factors such as the number of PV panels connected in series and parallel, the operating temperature of the electrolyzer and the number of stacks it comprises. Fig. 3 graphically illustrates the similarity in the characteristics of PV and electrolyzer systems, which facilitate the system to function as closely to MPP conditions as possible. A DC-DC converter is capable of injecting the maximum power of the PV system into the electrolyzer. An optimum operating condition is required for a directly coupled PV-electrolyzer since a simple prime sizing provides the required power for the electrolyzer. An optimization, at the same time, of the dimensions of the PV system for obtaining maximum hydrogen from the device is required.
This gives rise to a new optimization index in order to account for the changing price of the PV system. Hence, maximum hydrogen production of the electrolyzer module, minimum excess power generation of the PV module, and minimum power transfer loss form the foundational objectives for the optimization function proposed.

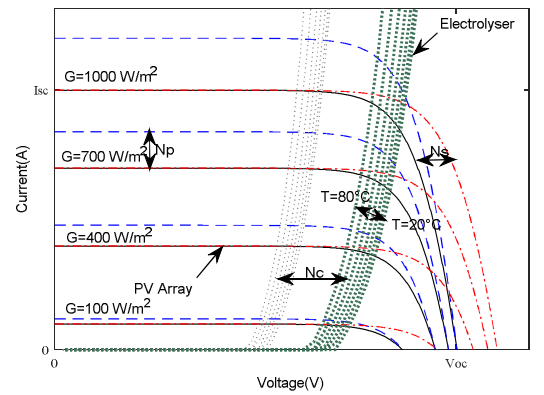

Fig. 3. U-I characteristics of photovoltaic system and alkaline electrolyzer

\section{RESULTS AND DISCUSSIONS}

The simulation results need to be accurate and as close to the real world scenarios. In order to achieve this goal, actual meteorological data for the city of Miami was obtained from its local utility. The gathered datasets comprised the data for temperatures and irradiation, as depicted in Figure 4, representing the average weather characteristics of the city. Miami has one of the most advantageous geographic locations in the world for receiving ample sunlight, considering its close proximity to the tropic of cancer with a latitude of $25.77^{\circ}$. This means that it is the most northerly circle of latitude on the planet where the sun might appear directly overhead at the peak. Defined in [26], the most appropriate values for $\beta$, which is the angle between the surface collector and the horizon, and $\gamma$, the surface azimuth angle, are the latitude of the region and zero, respectively. This ensures maximum irradiation reception as well.

The proposed system is subject to a two-level GA optimization process as shown in Fig. 5. While the first level focuses on optimizing the system's dimensions, the second level takes the dimensions of each iteration and optimizes the temperature of the system. It is noteworthy from [17] that minimum energy transfer loss does not necessarily imply maximum hydrogen production.

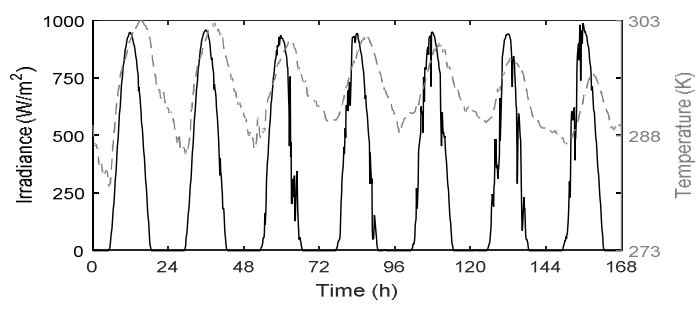

Fig. 4. Temperature and Irradiance of Miami for a day 
Hence, for optimum sizing of the system, the defined objective function has to be modified to include both maximum hydrogen production as well as minimum excess power transfer loss, which can be mathematically represented as shown below.

$$
\text { Objective_Function }=\text { Maximize }\left(\frac{\operatorname{Ave}\left(\frac{P_{\text {Actual }}}{P_{M P P}}\right) \cdot \dot{n}_{H 2}}{\operatorname{Ave}\left(P_{\text {Loss }}\right)}\right)
$$

The surplus power generated by the PV module, which exceeds the nominal power of the electrolyzer module, cannot be used because of which it is perceived to be lost. Although system cost is one of the primarily considered criteria for optimization studies, this paper addresses this factor in an indirect manner by optimizing parameters which drive the system's cost. Minimizing the excess power produced could be one viable substitution since it affects the cost of the system. When the system works in voltages other than that of the MPP, there is said to be some power transfer loss endured. To ensure the best operational conditions for the system, the temperature is optimized in each iteration. The temperature needs to iteratively optimized and hence adaptively evolving, because the results lose accuracy when this parameter is rigidly set fixed. It follows from the justified observation that each dimension of the system delivers maximum power at different specific temperatures.

TABLE III OPTIMIZATION RESULT

\begin{tabular}{ll}
\hline Parameter & Result \\
\hline PV Nominal Power & $12.4 \mathrm{~kW}$ \\
$\mathrm{~N}_{\mathrm{s}}$ & 2 \\
$\mathrm{~N}_{\mathrm{p}}$ & 133 \\
$\mathrm{~N}_{\mathrm{c}}$ & 21 \\
Average Temperature & $73^{\circ} \mathrm{C}$ \\
Average( $\left.\mathrm{V}_{\text {Direct }} / \mathrm{V}_{\mathrm{MPPT}}\right)$ & 0.80 \\
Average( $\left.\mathrm{P}_{\text {Direct }} / \mathrm{P}_{\mathrm{MPPT}}\right)$ & $97.57 \%$ \\
$\mathrm{P}_{\text {direct_Mean }}-\mathrm{P}_{\text {MPPT_Mean }}$ & $86 \mathrm{~W}$ \\
Hydrogen Production & $5322.9 \mathrm{~mol}$ \\
Energy Loss & $131.3 \mathrm{~kJ}$ \\
Average Daily Operation Voltage & $34.68 \mathrm{~V}$ \\
Total energy Consumption & $2.07 \mathrm{x} 10^{\wedge} 6 \mathrm{~kJ}$ \\
\hline
\end{tabular}

While the operating conditions of the electrolyzer and the ambient temperature play a major role in affecting the system's temperature, the system's cooling system with a controlled fluid flow rate and temperature can be instrumental in setting the system temperature to an optimum value. It encompasses 133 parallel rows of 2 panels in each. Since, as dictated by the Kirchhoff's Laws, the current is maximized through parallel connection, the number of PV panels wired in parallel is more than in series. From the GA optimization results tabulated in Table III, we infer that $12.4 \mathrm{~kW}$ is the optimal size of the PV array to supply the $10 \mathrm{~kW}$ alkaline electrolyzer with 21 stacks, all connected in series. It is worth mentioning that more current is required for voltages around $36 \mathrm{~V}$. In figures generated from the simulation, the projection of seven day operation is shown in blue color to show the variation of the parameters.

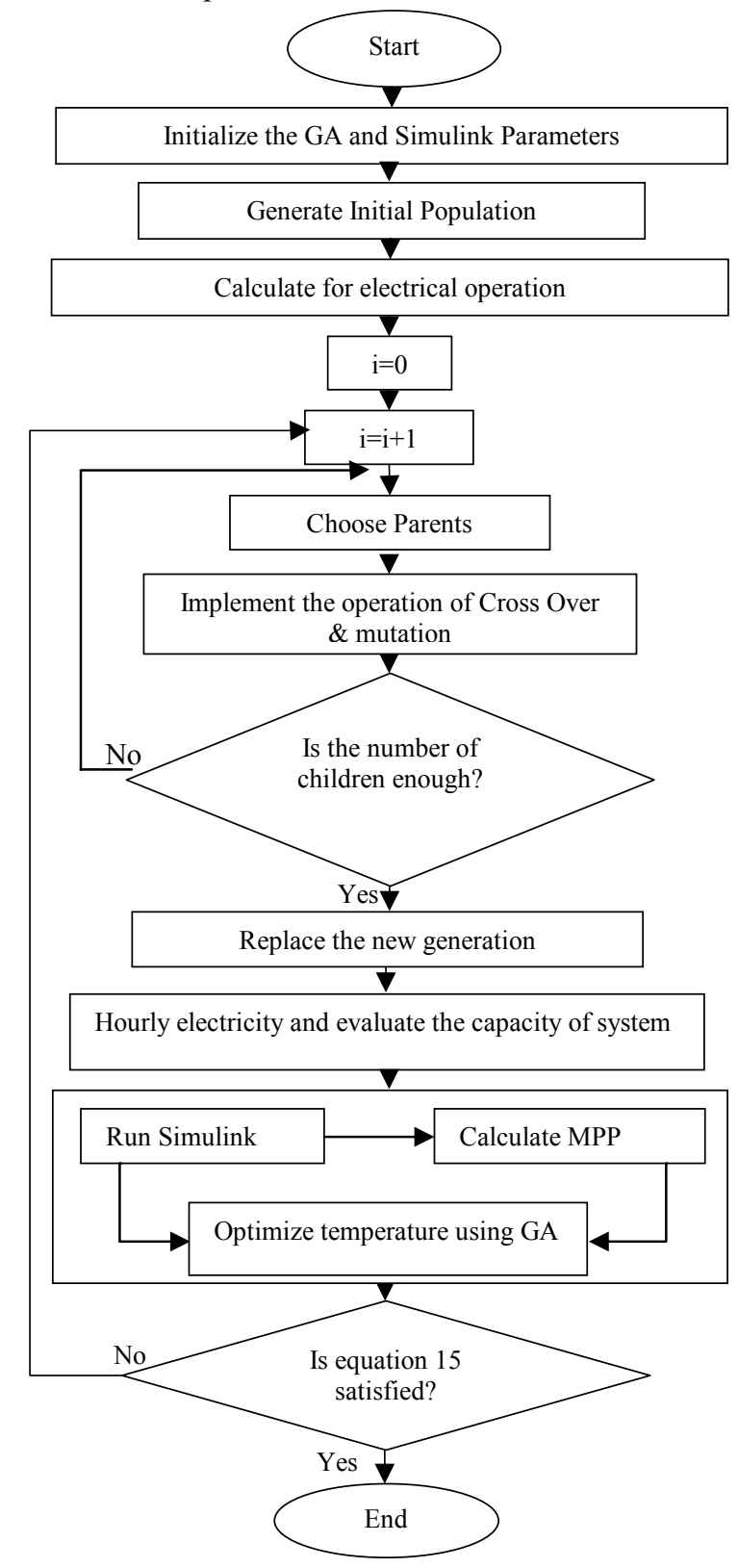

Fig. 5. Flowchart of the GA Optimization 
As can be seen from Fig. 6, the average operating voltage when the PV functions is $34.68 \mathrm{~V}$, which is 93.7 percent of the nominal operating voltage of the electrolyzer. Fig. 6b depicts the voltage pattern which also dictates the system current flow. It is decipherable that the average Faraday efficiency for the operating points is 83 percent, which is lower than 93.9 percent with regard to the maximum Faraday efficiency. Despite the average Faraday efficiency nearing its maximum value at higher temperatures, its variation at the proximity of nominal operating condition is negligible in contrast, as shown in the U-I characteristics below.

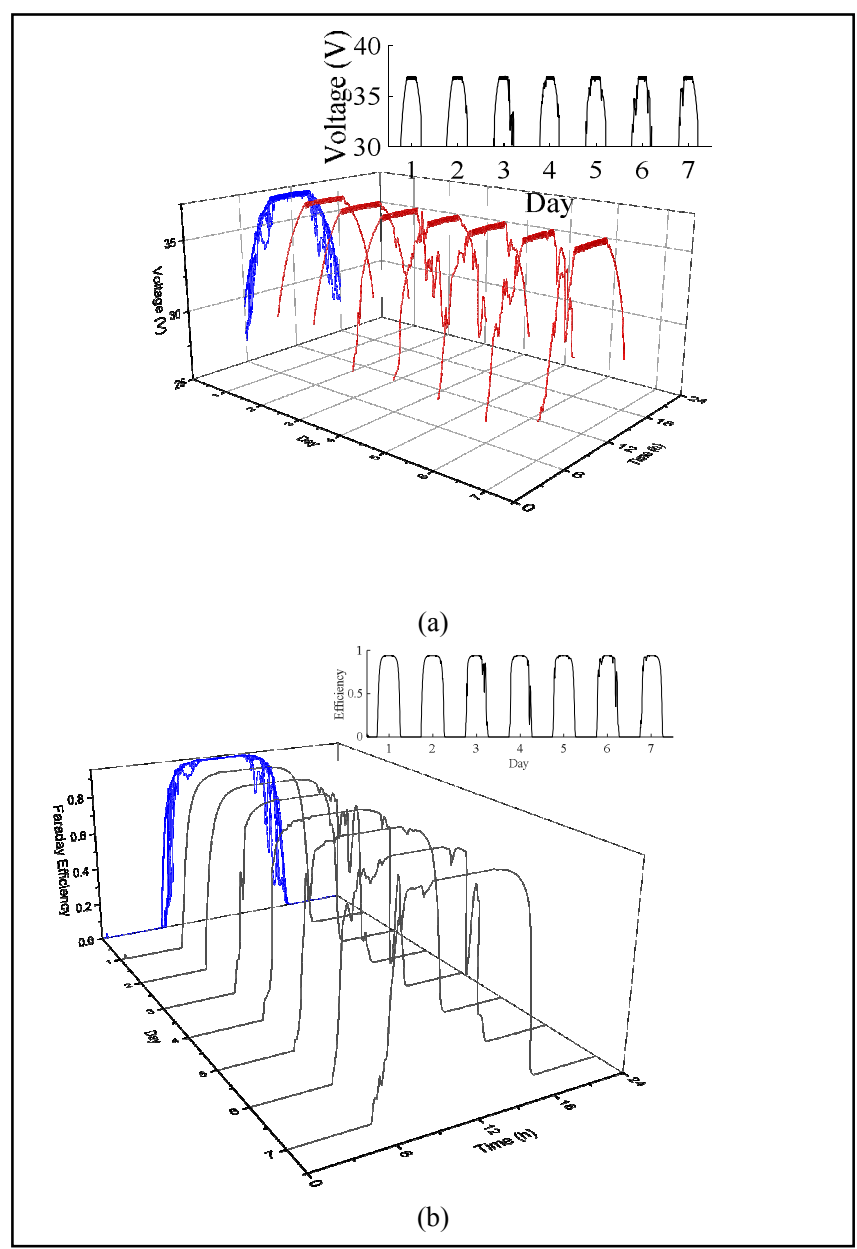

Fig. 6. Electrical characteristics of direct coupled PV-electrolyzer system

As observed from Fig. 7, which shows the curves for power production, consumption and the generated excess power with a detailed focus on the view of unused power, the average power production of photovoltaic system is $6.88 \mathrm{~kW}$ with an operating efficiency of 55.56 percent. Of that, while 93.7 percent is utilized by the electrolyzer, the rest is unused and hence must be minimized.

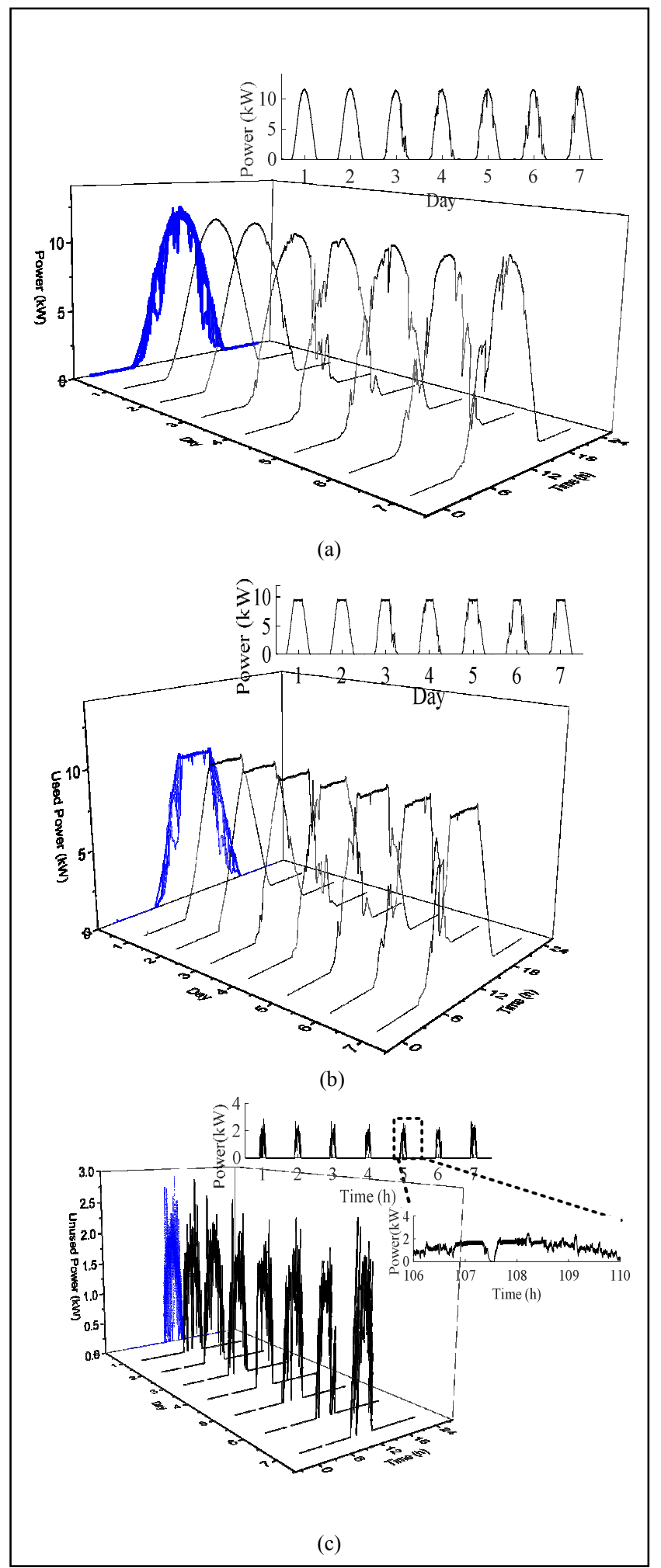

Fig. 7. Produced power of photovoltaic array (a) Consumed power by electrolyzer (b) and power loss (c) 
The power consumption is at its peak at noon, which implies there is a greater risk of producing higher magnitudes of unused power, since irradiation is available in surplus. At $10 \mathrm{~kW}, 63.89$ percent of the nominal power of the electrolyzer is the average power consumed by the device.

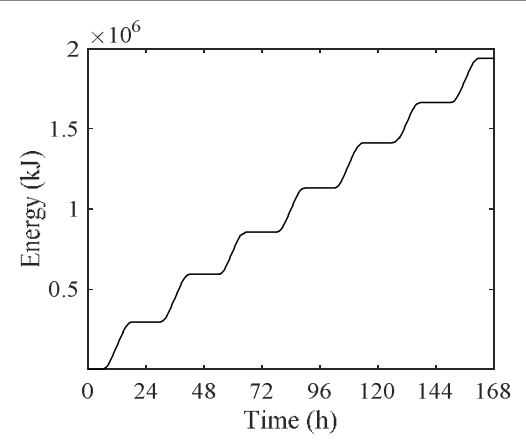

(a)

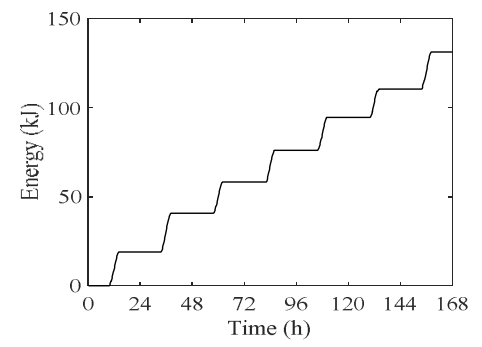

(b)

Fig. 8. Energy production (a) and loss (b) of the system

Fig. 8 can be used to evaluate the energy of the PV system to infer that the unused energy is about 0.006 percent of the produced amount, which can be ignored. This implies that the energy lost by the optimal system is quite low, essentially signifying that the PV production is in its most efficient mode yet. Other possible ways of energy production and consumption in the PV-electrolyzer environment such as thermal power have not been considered in this study. Instead, the produced energy is entirely credited to the electrical energy.

Fig. 9 displays the hydrogen production rate and pressure. For an operating time, the average rate of hydrogen production is $0.176 \mathrm{~mol} / \mathrm{s}$, while it is $0.0088 \mathrm{~mol} / \mathrm{s}$ for a period of 24 hours. Cumulative production of hydrogen at the end of the day is $5322.9 \mathrm{~mol}$ wherein the pressure in the storage tank varies from 3.59 through $6.31 \mathrm{MPa}$. The hydrogen tank is changed in a daily manner. A comparative simulation of the PV-electrolyzer system operation in both directly coupled and MPP modes is illustrated in Fig. 10, from which their close proximity to each other in both voltage and power outputs is quite evident.

The affordability of the proposed system over the traditional power electronic systems used for hydrogen production can be observed from the fact that the average voltage of the directly coupled system is just $3.81 \mathrm{~V}$ lower than that in the MPP mode.

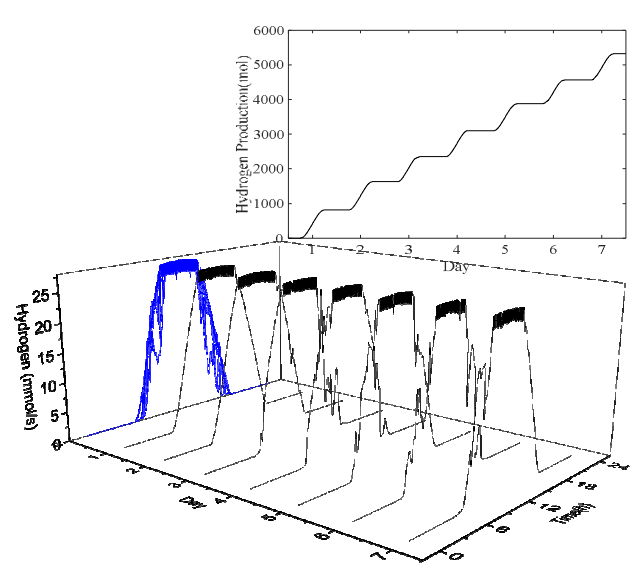

(a)

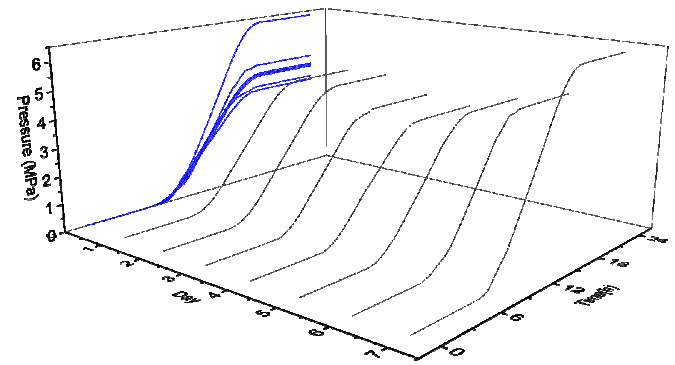

(b)

Fig. 9. Hydrogen production rate of the electrolyzer (a) and hydrogen storage pressure of tank (b)

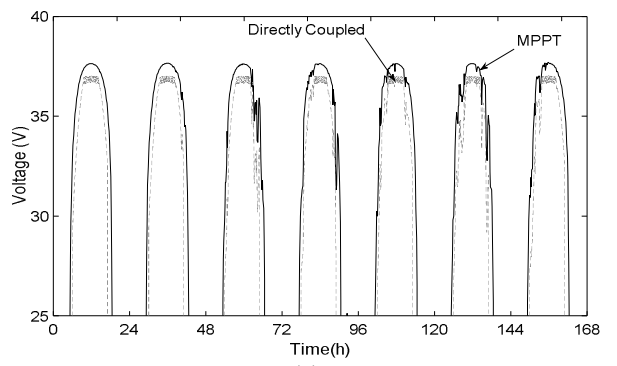

(a)

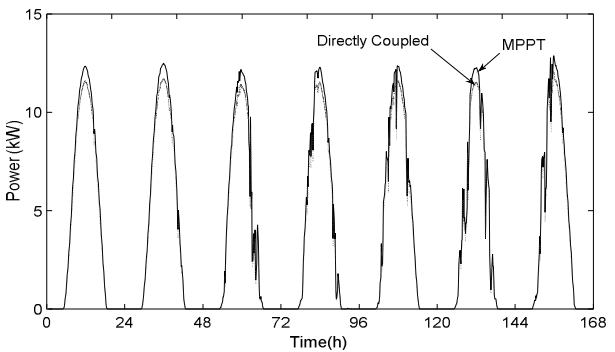

(b)

Fig. 10. Voltage (a) and power production (b) of photovoltaic array in directly coupled system and with MPPT 
Table II shows the average system specifications for the one week period of evaluation under conditions when there is significant irradiation available. This ensures that the system is rendered capable of standing for a comparison with other power production methods like the power sources of the electrolyzer.

As can be observed from the results, for the one week duration, the average amount of hydrogen generated is momentously lower than the operating time duration.

TABLE IV

AVERAGE SPECIFICATIONS OF THE SYSTEM IN 24 HOURS PERIOD AND IN BRIGHT HOURS WHEN THERE IS IRRADIATION

\begin{tabular}{|c|c|c|}
\hline & 24 hour-period & Bright hours \\
\hline Average Faraday Efficiency & 41.80 Percent & 83.03 Percent \\
\hline $\begin{array}{l}\text { Average Power consumption of } \\
\text { electrolyzer }\end{array}$ & $3.42 \mathrm{~kW}$ & $6.38 \mathrm{~kW}$ \\
\hline Average hydrogen production rate & $0.0088 \mathrm{~mol} / \mathrm{s}$ & $0.0176 \mathrm{~mol} / \mathrm{s}$ \\
\hline Average current & $89.48 \mathrm{~A}$ & $177.94 \mathrm{~A}$ \\
\hline Average Voltage & $16.08 \mathrm{~V}$ & $34.68 \mathrm{~V}$ \\
\hline Average Power loss & $0.131 \mathrm{~kW}$ & $0.434 \mathrm{~kW}$ \\
\hline
\end{tabular}

Provided in Table V is a comprehensive validation of the concerned study by comparing the results of the proposed system with two other similar systems. While the first study investigated an optimal direct coupling of the PV-hydrogen system with a PEM electrolyzer [27], the second study focused more on the reduction of the energy transfer loss using PSO [18].

TABLE V

COMPARISON OF THE OPERATION OF THE PROPOSED SYSTEM WITH REF [27].

\begin{tabular}{|c|c|c|c|}
\hline & Proposed Study & {$[27]$} & {$[18]$} \\
\hline Electrolyzer & $\begin{array}{l}\text { Advanced Alkaline } \\
\text { Electrolyzer }\end{array}$ & $\begin{array}{l}\text { PEM } \\
\text { Electrolyzer }\end{array}$ & $\begin{array}{l}\text { PEM } \\
\text { Electrolyzer }\end{array}$ \\
\hline $\begin{array}{l}\text { Connection } \\
\text { mode }\end{array}$ & Directly coupled & $\begin{array}{l}\text { Directly } \\
\text { coupled }\end{array}$ & $\begin{array}{l}\text { Directly } \\
\text { Coupled }\end{array}$ \\
\hline Objective & $\begin{array}{l}\text { Maximize } \\
\text { hydrogen, minimize } \\
\text { excess energy } \\
\text { production, } \\
\text { minimize energy } \\
\text { transfer loss, and } \\
\text { optimize operating } \\
\text { temperature }\end{array}$ & $\begin{array}{l}\text { Minimize the } \\
\text { energy loss }\end{array}$ & $\begin{array}{l}\text { Minimize the } \\
\text { energy transfer } \\
\text { loss }\end{array}$ \\
\hline $\begin{array}{l}\text { Optimization } \\
\text { method }\end{array}$ & $\begin{array}{l}\text { Two level Genetic } \\
\text { Algorithm }\end{array}$ & - & PSO \\
\hline Energy Transfer & $97.5 \%$ & $94 \%$ & $97.8 \%$ \\
\hline Energy loss & $6.3 \%$ & $5.82 \%$ & - \\
\hline
\end{tabular}

The optimization in the former was targeted towards minimizing the energy loss, compounding the observations with a global search between the different possible combinations to find the best result without employing any optimization in the first place, owing to the number of electrolyzers and panels.

While energy transfer is the difference of the actually delivered energy from the theoretical maximum deliverable energy, the total energy loss is the difference between the produced and the delivered power. For both of these aspects, the proposed PV-electrolyzer system delivers better results. As mentioned before, the second study is centered on the reduction of the energy transfer loss using PSO. However, it falls short in that the system thus developed might not necessarily function at its optimal point for generating maximum hydrogen. However, the system propositioned in this paper ensures hydrogen production optimization, along with minimized energy loss and overall efficiency enhancement, which is the most crucial factor for the best performance of the system, despite the energy transfer loss optimization being relatively lower.

\section{CONCLUSION}

This paper presented and discussed in detail the operations of directly coupled PV-electrolyzer system besides justifying its advantages over the contemporary power electronics based counterparts through profound simulative analysis for a period of one week on real-world, actual meteorological data collected from the local utility for the city of Miami. In comparison with those operating at MPP tracking modes, this system has just 2.43 percent power transfer loss. The system's efficiency was demonstrated through the U-I characteristics which fared better over those of the existing systems. A twofold GA based optimization enabled the use of optimal per iteration temperature for the system, thus enabling the system to get as close to the PV's MPP as possible. While it was observed that the optimal sizing of the system for generating maximum hydrogen of $5322 \mathrm{~mol}$ is accompanied by an average power loss of $434 \mathrm{~kW}$ for $12.4 \mathrm{~kW}$ PV system, an operating temperature of $73{ }^{\circ} \mathrm{C}$ complements the optimally sized system by aiding for higher efficiency with a final pressure of $6.31 \mathrm{MPa}$. Owing to the use of multi-level optimization and a generalized optimization objective function, a significant improvement of the proposed system is observed. For an optimal dimension, the system is found to operate efficiently without requiring power electronics-based devices making it more economically viable. A system is envisioned to be proposed as a future work, where actual operating temperature of the system along with optimized cooling system could be added to the design process for providing a result which is more precise.

\section{REFERENCES}

[1] E. Akyuza, Z. Oktay, I. and Dincerb, "Performance investigation of hydrogen production from a hybrid wind-PV system," Intl. J. Hydrogen Energy 2012; 37:16623-16630. 
[2] M.H. Etesami, M.M. Ardehali, "Newly Developed Enhanced Imperialistic Competitive Algorithm for Design Optimization of an Autonomous Hybrid Green Power System," Applied Mathematics \& Information Sciences 2014; 8(1): 309-320.

[3] S. Dutta, "A review on production, storage of hydrogen and its utilization as an energy resource," Journal of Industrial and Engineering Chemistry 2014; 20: 1148-1156.

[4] I. Dincer, T. Ratlamwala, "Development of novel renewable energy based hydrogen production systems: A comparative study," Energy Conversion and Management 2013; 72:77-87.

[5] M. Wang, Z. Wang, X. Gong and Z. Guo, "The intensification technologies to water electrolysis for hydrogen production - A review," Renewable and Sustainable Energy Reviews, Volume 29, January 2014, Pages 573-588.

[6] I. Ganeshan, V. Manikandan, V. Sundhar, R. Sajiv, C. Shanthi, S. Kottayil and T. Ramachandran, "Regulated hydrogen production using solar powered electrolyser," Intl. J. Hydrogen Energy, 2015: 1-5. Article in press.

[7] D. Scamman, H. Bustamante, S. Hallett and M. Newborough, "Offgrid solar-hydrogen generation by passive Electrolysis," Intl. J. Hydrogen Energy 2014;39:19855 -19868.

[8] E. Akyuz, C. Coskun, Z. Oktay and I. Dincer, "Hydrogen production probability distributions for a PV-electrolyser system," Intl. J. Hydrogen Energy, 2011; 36: 11292-11299.

[9] T. Gibson and N. Kelly, "Predicting efficiency of solar powered hydrogen generation using photovoltaic-electrolysis devices," Intl. J. Hydrogen Energy, 2010;35: 900-911.

[10] R. Garcia-Valverdea, C. Miguel, R. Martinez-Bejar and A. Urbina A., "Optimized photovoltaic generator-water electrolyser coupling through a controlled DC-DC converter," Intl. J. Hydrogen Energy, 2008; 33:5352 -5362

[11] Z. Ural and M. Gencoglu, "Design and simulation of a solar-hydrogen systemfor different situations," Intl. J. Hydrogen Energy, 2014;39: 8833-8840.

[12] A. Garrigos, J. Blanes, J. Carrasco, J.L. Lizan, R. Beneito and J.A. Molina. "5 kW DC/DC converter for hydrogen generation from photovoltaic sources," Intl. J. Hydrogen Energy, 2010;35(12):6123-30.

[13] R. Clarkea, S. Giddeya, F. Ciacchi, S. Badwal, B. Paul and J. Andrews, "Direct coupling of an electrolyser to a solar PV system for generating hydrogen," Intl. J. Hydrogen Energy, 2009;34: 2531-2542.

[14] A. Garrigos, J. Blanes, J. Rubiato, A vila E, C. Garcia, J. Lizan, "Direct coupling photovoltaic power regulator for stand-alone power systems with hydrogen generation," Intl. J. Hydrogen Energy, 2010;35: 10127 -10137.

[15] R. Garcia-Valverde, N. Espinosa, A. Urbina, "Optimized method for photovoltaic-water electrolyser direct coupling," Intl. J. Hydrogen Energy, 2011;36: 10574-10586.

[16] C. Zamfirescu, I. Dincer, "Assessment of a new integrated solar energy system for hydrogen production," Solar Energy, 2014;107: 700-713.

[17] A. Maroufmashat, F. Sayedin, S. Sattari Khavas, "An imperialist competitive algorithm approach for multi-objective optimization of direct coupling photovoltaic-electrolyzer systems," Intl. J. Hydrogen Energy, 2014;39: 18743 -18757.

[18] F. Sayedin, A. Maroufmashat, R. Roshandel, S. Sattari Khavas, "Optimal design and operation of a photovoltaic-electrolyser system using particle swarm optimization," International Journal of Sustainable Energy, 2014; 1-18.

[19] Z. Su, S. Ding, Z. Gan, X. Yang, "Optimization and sensitivity analysis of a photovoltaic-electrolyser direct-coupling system in Beijing," Intl. J. Hydrogen Energy, 2014;39: 7202-7215.

[20] Z. Yang, G. Zhang, B. Lin, "Performance evaluation and optimum analysis of a photovoltaic-driven electrolyzer system for hydrogen production," Intl. J. Hydrogen Energy, 2015;40:3170-3179.

[21] Ø Ulleberg. "Modeling of advanced alkaline electrolyzers: a system simulation approach," Intl. J. Hydrogen Energy 2003; 28:21-33.

[22] A. Khalilnejad, G. Riahy, "A hybrid wind-PV system performance investigation for the purpose of maximum hydrogen production and storage using advanced alkaline electrolyzer," Energy Conversion and Management, 2014; 80: 398-406.

[23] H. Gholami, A.I. Sarwat, H. Hosseinian, A. Khalilnejad, "Evaluation of optimal dual axis concentrated photovoltaic thermal system with active ventilation using Frog Leap algorithm," Energy Conversion and Management, 2015;105: 782-790.

[24] D. Jena, V. Ramana, "Modeling of photovoltaic system for uniform and non-uniform irradiance: A critical review," Renewable and Sustainable Energy Reviews, 2015; 52: 400-417.

[25] A. Loukriz, M. Haddadi, S. Messalti, "Simulation and experimental design of a new advanced variable step size Incremental Conductance MPPT algorithm for PV systems," ISA Transactions, Article in press

[26] H. Gholami, A. Khalilnejad, G. Gharehpetian, "Electrothermal performance and environmental effects of optimal photovoltaicthermal system," Energy Conversion and Management, 2015; 95: 326333.

[27] B. Paul, J. Andrews, "Optimal coupling of PV arrays to PEM electrolysers in solar-hydrogen systems for remote area power supply," Intl. J. Hydrogen Energy, 2008;33: 490- 498.

[28] O. Palizban, M.A. Razaei, S. Mekhilef, "Active and reactive power control for a hybrid system with photovoltaic panel, wind turbine, fuel cells, electrolyzer and super capacitor in off-grid mode," IEEE International Conference on Control System, Computing and Engineering (ICCSCE), 2011; pp. 404-408, DOI: 10.1109/ICCSCE.2011.6190560

[29] C. Wang, M.H. Nehrir. "Power Management of a Stand-Alone Wind/Photovoltaic/Fuel Cell Energy System," IEEE Transactions on Energy Conversion, Vol. 23, No. 3, September 2008

[30] P.K. Saini, A. Biswas, D. Bhanja, "Performance Evaluation and Simulation of Solar Panel, Wind Mill, Fuel Cell Hybrid System for Small Scale Energy Harvesting," Journal of Clean Energy Technologies Vol. 3, No. 6, November 2015

[31] O.H. Mohammed, Y. Amirat, M. Benbouzid, "Optimal Design of a PV/Fuel Cell Hybrid Power System for the City of Brest in France," IEEE IGCE 2014

[32] A. Sathyan, K. Anthony, S. Al-Hallaj, "Hybrid wind/PV/fuel cell generation system," IEEE Conference on Vehicle Power and Propulsion 2005, DOI: 10.1109/VPPC.2005.1554604

[33] D. Sharma, R.S. Meena, D.K. Birla, "PV-Wind System with Fuel Cell \& Electrolyzer," International Journal of Engineering Research, December 2015, Vol. 4, Issue 12, pp. 673-679

[34] S. Esmaeili, M. Sahfiee, "Simulation of Dynamic Response of Small Wind-Photovoltaic-Fuel Cell Hybrid Energy System," Smart Grid and Renewable Energy, 2012, Vol. 3, pp. 194-203, DOI: http://dx.doi.org/10.4236/sgre.2012.33027

[35] M.S. Alam, D.W. Gao, "Modeling and Analysis of a Wind/PV/Fuel Cell Hybrid Power System in HOMER," IEEE Conference on Industrial Electronics and Applications, 2007, pp. 1594-1599, DOI: 10.1109/ICIEA.2007.4318677 